\title{
Managing children with Medulloblastoma Algerian experience
}

\section{K.Ezziane $^{1^{*}}$, M Bouallag ${ }^{2}$, N. Habchi ${ }^{2}$, M.Mahiou ${ }^{3}$, K.Bouzid ${ }^{1}$}

${ }^{1}$ Pediatric oncology, Pierre \& Marie Curie Center, Algiers, Algeria.

${ }^{2}$ Department of neurosurgery Mustapha Pacha hospital, Algiers, Algeria

${ }^{3}$ Department of radiotherapy, Pierre \& Marie Curie Center, Algiers, Algeria.

*Corresponding Author: K.Ezziane, Pediatric oncology Pierre \& Marie Curie Center, Algiers, Algeria. Pediatric oncology,

Pierre \& Marie Curie Center, Algiers, Algeria.

Received date: April 23, 2020; Accepted date: June 27, 2020; Published date: July 15, 2020.

Citation: K.Ezziane, M Bouallag, N. Habchi, M.Mahiou, K.Bouzid, (2020) Managing children with Medulloblastoma Algerian experience J Neuroscience and Neurological Surgery. 6(4); DOI:10.31579/2578-8868/128

Copyright: (92020 K.Ezziane, This is an open-access article distributed under the terms of the Creative Commons Attribution License, which permits unrestricted use, distribution, and reproduction in any medium, provided the original author and source are credited.

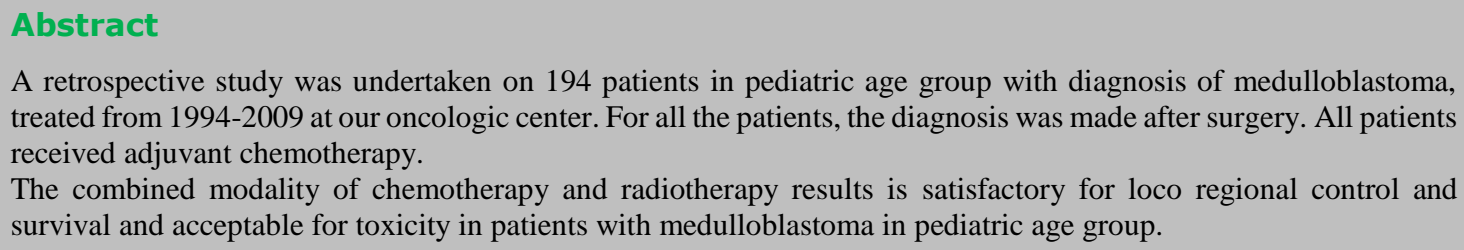
treated from 1994-2009 at our oncologic center. For all the patients, the diagnosis was made after surgery. All patients received adjuvant chemotherapy.

The combined modality of chemotherapy and radiotherapy results is satisfactory for loco regional control and survival and acceptable for toxicity in patients with medulloblastoma in pediatric age group.

Key words: medulloblastoma, managing, results, key for progress.

\section{Introduction}

While leukemias are the most common type of malignancy to afflict the pediatric population, brain tumors are the most common solid tumors in this age group. [1] Medulloblastoma is the most common malignant brain tumor in children constituting nearly $20 \%$ of all pediatric brain tumors. [2]. It is categorized as an embryonal neuroepithelial tumor of the cerebellum. This is a high-grade tumor that has a propensity to spread via the cerebrospinal fluid.

\section{Objetives:}

The objectif of our work is to establish the characteristics and outcome of the patients with medulloblastoma in pediatric age group.

\section{MATERIAL AND METHODS:}

A retrospective study was undertaken on 194 patients in pediatric age group with diagnosis of medulloblastoma, treated from 1994-2009 at our oncologic center. For all the patients, the diagnosis was made after clinical examination, imagery and surgery.

\section{Post-operative treatment:}

All patients have received the adjuvant treatment wich depended on the stage of the disease. This treatment was based on chemotherapy, including eight drugs in one day:vincristine, bicnu, solumedrol, natulan, hydrea, cisplatinum, aracytine, endoxan, (6 courses from the $1^{\text {st }}$ day to $21^{\text {th }}$ day). Since 2004 , they received two drugs: carboplatine and etoposide ( 4 courses from the $1^{\text {st }}$ day to $28^{\text {th }}$ day). Under 5 years old, they received BBSFOP protocol, 7 cycles.

For the radiation therapy they received 55Gys for posterior fossa and 35 Gyscranio for the spinal axis.

\section{RESULTS:}

The patients age was from 3 months to 20 years with middle age of 6,7 years. The sex ratio woman / man was $1,6.18 \%$ of patients didn't' have residue or metastasis- $82 \%$ of patients had residue or metastasis (figure 1, tables 1and 2). 
Table 1: chang staging

\section{CHANG staging}

- G1 : total or subtotal removal of the tumor, no evidence of metastasis disease: $18 \%$.

- G2 : gross residual tumor, metastases in the central nervous system: $82 \%$.
Table 2: Os/extent of disease

\begin{tabular}{|c|c|c|}
\hline & 3 years & 5 years \\
\hline G1 & $65 \%$ & $60 \%$ \\
\hline G2 M- & $45 \%$ & $26 \%$ \\
\hline G2 M+ & $19 \%$ & $1 \%$ \\
\hline
\end{tabular}

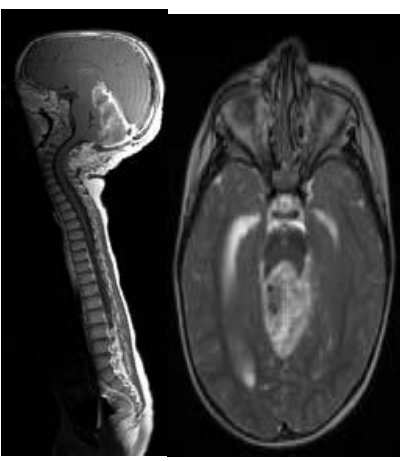

Figure 1: cerebro spinal MRI show the extention of the medulloblasstoma

Histological examination revealed: 89\% classical medulloblastoma (174 cases), 7\% desmoplasic (13 cases) and 4\% anaplasia (7 cases) (Figure2a). The distribution of percentages by age is demonstrated in the figure $2 \mathrm{~b}$.

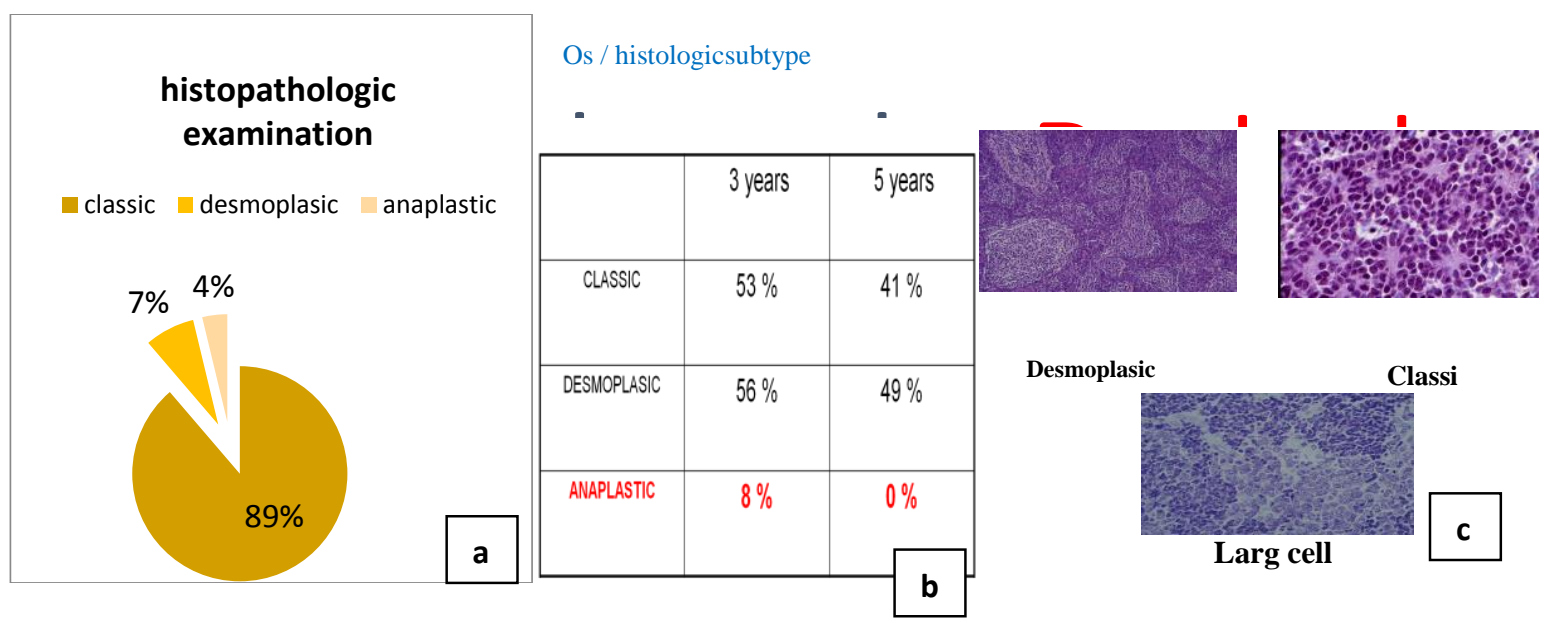

a: percentage
of histological subtype
Figure 2: Histopathological examination

b: distribution of histological subtype depend on the age c : microscopic illustration of histological subtype
Late effects that appeared after the radiotherapy are:

Neurological deficit (55\%), endocrine deficit (21\%), TSH-GH Short stature $(\mathrm{RTH}+/-\mathrm{GH})$, Neuropsychological disorder (35\%) as school failure.
The evaluation was done after the Clinical examination, Lumbar puncture for CSF cytology and imagery (brain MRI or CT scan).

The combined modality of chemotherapy and radiotherapy revealed: $68 \%$ partial response, $13,6 \%$ stabilizations and $18,4 \%$ progression. After median follow-up of 48 months, overall survival and disease free survival for entire group was $60 \%$ and $45 \%$. 


\section{DISCUSSION:}

Within the first few years of diagnosis of the medulloblastoma, mortality approximates $15 \%$; however, cure rates can reach as high as $60 \%$ with current therapeutic modalities.[3][4] Surgical resection preceded and/or followed by radiation and chemotherapy is the mainstay of therapy, with five-year survival rates of between $50 \%$ to $90 \%$. This wide range is multifactorial, owing in part to age at diagnosis, the presence of metastases at diagnosis, and a histologic variant of medulloblastoma.[1][5] Regardless of long-term survival, treatment-related cognitive, neurologic, and endocrinologic effects remain a debilitating concern and an impetus for the search for further therapeutic modalities.

Current treatment modalities for medulloblastoma combine surgical resection with chemotherapy and radiation. By traditional risk stratification, cure rates in the average-risk group reached threequarters of patients. However, post-surgical treatment-related neurologic, cognitive, and endocrinologic sequelae, including intellectual retardation and growth hormone deficiency, remain a source of morbidity in up to $80 \%$ of survivors. The high-risk group experienced up to $50 \%$ mortality due not only to the presence of extraneural metastases at diagnosis but also due to their young age at diagnosis, which poses significant limitations to their therapeutic options, namely lower doses of radiation and chemotherapeutic agents.[1]

\section{CONCLUSION:}

medulloblastoma management strategies, which encompass surgical resection of the tumour, cranio-spinal irradiation and chemotherapy, are discussed, together with the possibility of focusing more on disease biology and robust molecularly driven patient stratification in future clinical trials.

\section{REFERENCES:}

1. Gilbertson RJ, Medulloblastoma: signalling a change in treatment. The Lancet. Oncology. 2004 Apr;

2. Rossi A,Caracciolo V,Russo G,Reiss K,Giordano A, Medulloblastoma: from molecular pathology to therapy. Clinical cancer research : an official journal of the American Association for Cancer Research. 2008 Feb 15;

3. Pfister S,Remke M,Benner A,Mendrzyk F,Toedt G,Felsberg J,Wittmann A,Devens F,Gerber NU,Joos S,Kulozik A,Reifenberger G,Rutkowski S,Wiestler OD,Radlwimmer B,Scheurlen W,Lichter P,Korshunov A, Outcome prediction in pediatric medulloblastoma based on DNA copy-number aberrations of chromosomes $6 q$ and $17 q$ and the MYC and MYCN loci. Journal of clinical oncology : official journal of the American Society of Clinical Oncology. 2009 Apr 1;

4. Wu X,Northcott PA,Croul S, Taylor MD, Mouse models of medulloblastoma. Chinese journal of cancer. $2011 \mathrm{Jul}$;

5. Huse JT,Holland EC, Genetically engineered mouse models of brain cancer and the promise of preclinical testing. Brain pathology (Zurich, Switzerland). 2009 Jan;

6. Bunin GR,Kushi LH,Gallagher PR,Rorke-Adams LB,McBride ML,Cnaan A, Maternal diet during pregnancy and its association with medulloblastoma in children: a children's oncology group study (United States). Cancer causes
This work is licensed under Creative Commons Attribution 4.0 License

To Submit Your Article Click Here: Submit Manuscript

DOI: $10.31579 / 2578-8868 / 128$
Ready to submit your research? Choose Auctores and benefit from:

$$
\begin{aligned}
& \text { * fast, convenient online submission } \\
& \text { rigorous peer review by experienced research in your field } \\
& \text { *apid publication on acceptance } \\
& \text { * authors retain copyrights } \\
& \text { * immediate, unrestricted online access }
\end{aligned}
$$

At Auctores, research is always in progress.

Learn more www.auctoresonline.org/journals/neuroscience-andneurological-surgery 